Scientia Agricola

http://dx.doi.org/10.1590/0103-9016-2015-0290

Review

\title{
Sulfites in beer: reviewing regulation, analysis and role
}

\author{
Luis F. Guido*
}

University of Porto/Faculty of Science - Dept. of Chemistry and Biochemistry - REQUIMTE/LAQV, R. do Campo Alegre, 687 - 4169-007 - Porto - Portugal.

*Corresponding author <lfguido@fc.up.pt>

Edited by: Paulo Cesar Sentelhas

\begin{abstract}
Beer is an extremely complex mixture of more than 3,000 different compounds in an aqueous environment. Thus, it is perhaps not surprising that the maintenance of beer quality throughout its lifetime has been a considerable challenge for brewers. Whilst it is inevitable that chemical changes will occur in beer with the passage of time, it is the formation of flavor-active components which is of immediate concern to an overview of beer shelf life stability. Sulfur dioxide has long been recognized by brewers as the most important factor in delaying flavor staling, and prolonging the shelf life of beer. However, nowadays, sulfur dioxide and sulfites are considered allergens and concerns about the safety of their use as food additives have been on the increase. The present review is structured into three main parts. Firstly, the chemical properties of sulfur dioxide are presented, along with the toxic effects and maximum legal levels permitted according to U.S. and EU legislation. As the accurate determination of the free, bound and total sulfur dioxide in beer is essential to ensuring regulatory compliance, several methods have been developed for analyzing sulfur dioxide in beer. Thus, secondly, various types of methods are reported and compared with the officially recommended ones. Finally, the crucial role of sulfite in the control of flavor instability of beer is discussed in light of the current data. Two courses of action have been proposed, which are elucidated in detail relating firstly to the fact that sulfite inhibits beer oxidation during storage by acting as an antioxidant and, secondly, sulfite reacts with the carbonyl staling compounds in beer, and thereby masks stale flavors.

Keywords: beer flavour, sulfur dioxide, legislation toxic effects, antioxidants
\end{abstract}

ic studies revealed that undissociated sulfurous acid, $\mathrm{H}_{2} \mathrm{SO}_{3^{\prime}}$ may be assumed to be a short-lived intermediate in the acidification of sulfites, but does not exist in detectable amounts in aqueous solutions of sulfur dioxide (Senning, 1982). At the usual $\mathrm{pH}$ of beers $(3.8-4.4)$, most of the $\mathrm{SO}_{2}$ is present as the bisulfite (or hydrogen sulfite) anion, as illustrated in Figure 1.

Sulfur dioxide, sulfurous acid and sulfites can function as mild oxidizing agents; however, reactions in which these compounds react as reducing agents (and are oxidized to the sulfate ion, $\mathrm{SO}_{4}{ }^{2-}$ ) are more numerous and more important (Earnshaw, 1999), and a comprehensive monograph on the chemistry of sulfur dioxide in foods has been published (Wedzicha, 1984). In the present review, the terms sulfur dioxide and sulfite will be used interchangeably to represent all forms of $\mathrm{SO}_{2}$.

Sulfites occur naturally in a number of foods and beverages as a result of fermentation, such as occurs in beer and wine. As a food additive, sulfites have been used since 1664 and have been approved for use in the United States since the 1800s (Lester, 1995). With such a history of widespread application, sulfites have been generally regarded as safe (GRAS) by the FD; however, it is suspected that a low percentage of the population is sensitive to sulfites. The manifestations of sulfite sensitivity include a large array of dermatological, pulmonary, gastrointestinal, and cardiovascular symptoms. Asthmatics, for example, who are steroid-dependent or have a great degree of airway hyperreactivity may be at an increased risk of having a reaction to a sulfite-containing 
Table 1 - Selected molecular and physical properties of $\mathrm{SO}_{2}$ (adapted from Greenwood and Earnshow, 1999).

\begin{tabular}{llll}
\hline Property & Value & Property & Value \\
\hline $\mathrm{MP} /{ }^{\circ} \mathrm{C}$ & -75.5 & Electrical conductivity $\kappa / \mathrm{ohm}^{-1} \mathrm{~cm}^{-1}$ & $<10^{-8}$ \\
$\mathrm{BP} /{ }^{\circ} \mathrm{C}$ & -10.0 & Dielectric constant $\varepsilon\left(0^{\circ}\right)$ & 15.4 \\
Critical temperature $/{ }^{\mathrm{a} C}$ & 157.5 & Dipole moment $\mu / \mathrm{D}$ & 1.62 \\
Critical pressure $/ \mathrm{atm}$ & 77.7 & Angle O-S-O & $119^{\circ}$ \\
Density $\left(-10^{\circ}\right) / \mathrm{g} \mathrm{cm}-3$ & 1.46 & Distance $\mathrm{r}(\mathrm{S}-0) / \mathrm{pm}$ & 143.1 \\
Viscosity $\eta\left(0^{\circ} \mathrm{C}\right) /$ centipoise & 0.403 & $\Delta \mathrm{H}_{\mathrm{f}}^{\circ}(\mathrm{g}) / \mathrm{kJ} \mathrm{mol}-1$ & -296.9 \\
\hline
\end{tabular}

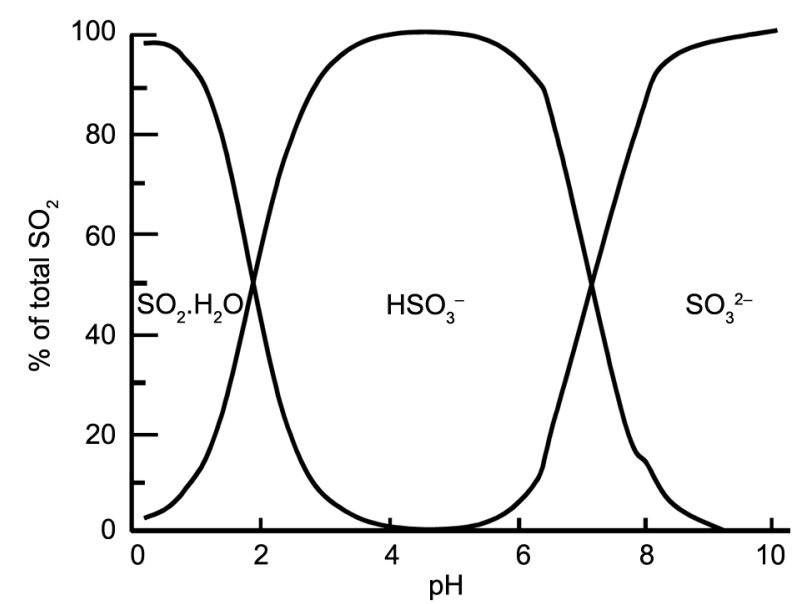

Figure 1 - The effect of $\mathrm{pH}$ on the equilibria of $\mathrm{SO}_{2}$ species in aqueous solution (adapted from llett, 1995).

food (Lester, 1995). As a result, sulfiting agents are not considered GRAS for use in meats, i.e. foods recognized as a major source of vitamin B1 (thiamine), or "fruits or vegetables intended to be served raw to consumers or to be presented to consumers as fresh" (FDA, 1988).

The European Commission's Scientific Committee on Food (SCF) put forward in 1994 an acceptable daily intake (ADI) of $0.7 \mathrm{mg} \mathrm{kg}^{-1}$ body weight/day for sulfur dioxide and sulfur dioxide equivalents (SCF, 1994). The ADI is the amount of food additive, expressed on a body weight basis, which can be ingested daily over a lifetime without appreciable health risk. Toxicity was in part attributed to the well-known destructive action of sulfite on thiamine. It has been suggested that the ingestion of $\mathrm{SO}_{2}$ in a beverage may effectively reduce the level of thiamine in the rest of the diet (Cremer and Hotzel, 1970). Human studies over short periods showed that $400 \mathrm{mg}$ $\mathrm{d}^{-1}$ produced no effect on thiamine excretion. Sulfites have also a certain irritant action on the skin, but the risks involved in handling these compounds are apparently rather small (Senning, 1982).

The use of sulfites in food products became an issue of concern to both consumer and regulatory agencies when it was found that certain sensitive individuals exhibited adverse reactions to sulfite residues in foods. Further investigations into this potential health hazard led agencies to promulgate regulations concerning the usage and labelling of sulfiting agents. Brewers can pro- duce beers with a sulfite content well below $10 \mathrm{mg} \mathrm{L}^{-1}$, the level at which declaration of sulfites has been mandated for the labelling of alcoholic beverages by both US and EU legislation. The statement "Contains sulfites" or "Contains (a) sulfiting agent(s)" or a statement identifying the specific sulfiting agent where sulfur dioxide or a sulfiting agent is detected at a level of 10 or more parts per million (ppm), measured as total sulfur dioxide, is mandatory in the USA (GPO, 2000). The 2000/13/EC Directive from the European Parliament and Council on the labelling of foodstuffs (EC, 2000) requires sulfur dioxide and/ or sulfites to be labeled when present in beer above $10 \mathrm{mg} \mathrm{L}^{-1}$ (calculated in terms of the total $\mathrm{SO}_{2}$ ). For products where a list of ingredients is not required (e.g. alcoholic beverages with $>1.2 \%$ by volume of alcohol) the presence of the allergen must still be shown on the label e.g. 'contains sulfur dioxide'. In Canada, the new food allergen labelling regulations require that sulfites at a level of $10 \mathrm{ppm}$ or more must be declared when present in alcoholic beverages. Beer, ale, stout, porter and malt liquor are exempt from the requirement to declare food allergen, gluten or added sulfites unless a list of ingredients is shown on the product's label in a statement entitled 'Contains'. Any list of ingredients that is voluntarily provided must be complete, and declare all priority allergens and gluten sources, and added sulfites when present at 10 ppm or more [B.01.010.2, B.01.010.3, Food and Drug Regulations] (Government of Canada, 2015). Brazil's regulatory agency (ANVISA, 2011) issued a resolution (Resolution RDC No 65 of 29 November 2011) establishing a maximum legal limit of $0.005 \mathrm{~g} / 100 \mathrm{~g}$ or $0.005 \mathrm{~g} / 100 \mathrm{~mL}$ to earn a free of total sulfur dioxide in beer classification (Brazil, 2011).

\section{Sulfur dioxide analysis in beer}

Potential problems with the usage of sulfiting agents in foods and the investigations revealing wide and increased utilization of these compounds in foodstuffs have raised questions as to the suitability of available methodologies for determining sulfites in food and beverages. Many methods are currently in use, varying in specificity and sensitivity, applicable to specific matrices but lacking a suitable data-base for comparison with each other.

Currently, many different procedures are being used by the industry to determine the sulfite content of their products including various versions of the classical Monier-Williams method, colorimetric procedures 
such as the $p$-rosaniline and to a limited extent, flow injection analysis, pulse polarography and ion chromatography. The Monier-Williams method has been the reference method for many years, but it has drawbacks at the $10 \mathrm{mg} \mathrm{L}^{-1}$ level. Minor procedural changes made to the Monier-Williams method by the Food and Drug Administration (FDA) improved accuracy at the $10 \mathrm{ppm}$ level used in the labelling of sulfite content in commercial products (Bubnis, 1988). The Monier-Williams technique, adopted by the Institute of Brewing, involves the removal of $\mathrm{SO}_{2}$ from acidified beer in a stream of carbon dioxide and nitrogen at $100{ }^{\circ} \mathrm{C}$. The gas is absorbed in hydrogen peroxide and the sulfuric acid formed titrated against $\mathrm{NaOH}$. Minor modifications made by the FDA include reduction in concentration of the titrant by a factor of 10, the replacement of the pyrogallol trap by a GLC-type oxygen scrubber and elimination of the hot condenser step (Fazio, 1988; Fazio and Warner, 1990). A coulometric adaptation of the Monier-Williams method yielded significant correlation with the $p$-rosaniline reference method, permitting a reduced sample size while improving precision and significantly reducing analysis time (Zeller, 1988).

The colorimetric method using rosaniline hydrochloride was adopted by the American Society of Brewing Chemists (ASBC). This method proved to be quite acceptable until the last few years when questions about the carcinogenicity of the $p$-rosaniline reagent were raised. This colorimetric analysis is based on the reaction between $\mathrm{SO}_{2}, p$-rosaniline and formaldehyde. After reaction with $p$-rosaniline and development of the color for 30 minutes, the absorbance of the $p$-rosaniline-sulfite complex is measured at $550 \mathrm{~nm}$. This method has been widely used as it is precise and allows for measurement of free and total $\mathrm{SO}_{2}$. Another colorimetric method uses DTNB, which is 5.5-dithiobis (2-nitrobenzoic acid), as the color reagent after a distillation step. It is a method for total $\mathrm{SO}_{2}$ determination in beer recommended by the EBC. Sulfur dioxide is distilled from acidified $25 \mathrm{~mL}$ samples into a buffered DTNB solution, with a nitrogen carrier gas, and absorbance is measured at $415 \mathrm{~nm}$. A simpler version of the DTNB method has been recently applied to beer samples with $97 \%$ of sulfite recovery ( $\mathrm{Li}$ and Zhao, 2006).

During the past few years, flow injection analysis (FIA) methods for determining sulfites in beer and other beverages have been widely developed. Most flow injection analyses are adaptations of other existing methods, mainly spectrophotometric methods. Application of FIA systems for both the malachite green (Atanassov et al., 2000; Bendtsen and Jorgensen, 1994) and $p$-rosaniline (Fernandes et al., 1998) methods are known. The sample is injected into the carrier stream which contains $\mathrm{NaOH}$ for on-line release of bound sulfites. Sulfuric acid is introduced to lower the $\mathrm{pH}$ and convert all existing equilibrium products into the sulfur dioxide form which then diffuses across a gas permeable membrane. The sulfur dioxide is then reacted with malachite green or $p$-rosaniline to give a colored product which is measured using a spectrophotometer. Several applications of FIA towards the determination of sulfite in wine by spectrophotometric detection have been recently reported (Maquieira et al., 1993; Decnop-Weever and Kraak, 1997; Richter et al., 1993; Gonçalves et al., 2010).

A chronopotentiometric method for the on-line determination of total sulfur dioxide in beer has been reported (Dvořák et al., 2006). Free and bound sulfites were converted to sulfite anions on alkalising the sample solutions. On acidifying the solution, the sulfur dioxide released was separated on-line through a semipermeable membrane and transported by an electrolyte into the measuring cell and measured by stripping chronopotentiometry. The results corresponded well with those obtained with the alternative EBC methods, with the advantage of being much faster and simpler.

An enzymatic assay employing sulfite reductase is currently recommended by the EBC (Method 9.25.2, $\mathrm{EBC}, 1987)$. It is based on the oxidation of NADH by the hydrogen peroxide formed during the oxidation of sulfite by the action of sulfite oxidase. Changes in absorbance of NADH at $340 \mathrm{~nm}$ are used for determining the concentration of total sulfite.

Since the advent of flame photometric detection (FPD), the use of various gas chromatographic methods has been reported (Moreno and Vega, 1989) using GC to accurately quantify the amount of $\mathrm{SO}_{2}$ in beer. A method for the routine determination of both free and total sulfur dioxide residues in malt and total $\mathrm{SO}_{2}$ in beer using the technique of headspace GC was developed by $\mathrm{Mu}$ nar and co-authors (Munar et al., 1994). They showed that both the colorimetric and the headspace methods are comparable. The use of a highly sensitive and selective chemiluminescence sulfur detector was reported (Osborne, 1992; Burmeister et al., 1992). The sulfur chemiluminescence detector was evaluated as a replacement for the FPD as it was found to have better selectivity, sensitivity, and linearity. It was not susceptible to hydrocarbon-quenching effects shown by the FPD detector. These methods have the additional advantage over the colorimetric methods for dark beers.

Ion exclusion chromatography with electrochemical detection was proven to be a lot simpler and quicker with the results compared more favourably with the Monier-Williams technique and to correlate well with the $p$-rosaniline technique (Kim, 1990; Wygant et al., 1997). This method showed good reproducibility at levels close to $0.5 \mathrm{mg} \mathrm{L}^{-1}$ and an analysis time of approximately half an hour. Wagner and McGarrity used ion exclusion chromatography with pulsed amperometric detection to avoid the loss of detector sensitivity that occurs over time when direct amperometry is used (Wagner and McGarrity, 1991; Wagner and McGarrity, 1992).

A rapid and sensitive polarographic method was also presented for determining sulfiting agents in foods and beverages (Stonys, 1987; Holak and Patel, 1987). This method is based on the modified Monier-Williams distil- 
lation followed by polarographic detection by differential pulse polarography or square wave voltammetry and is specific for total $\mathrm{SO}_{2}$. A method involving voltammetric determination of free and total sulfur dioxide in beer was reported by Almeida et al., (2003). Voltammetric determinations are in agreement with those obtained by the $p$-rosaniline reference method, with the advantage of excluding the use of toxic reagents and providing more accurate and precise results.

More recently, a method was developed for the quantification of sulfite in beer based on derivatization with the maleimide-derived probe ThioGlo I followed by separation of fluorescent adducts by reversed-phase, high-performance liquid chromatography and fluorescence detection. ThioGlo I was found to have generated fluorescent adducts with both bound and free sulfites, providing a quantification of total sulfite content in beer. The limit of quantification of sulfite was $0.6 \mathrm{mg} \mathrm{L}^{-1}$ and the method can be used for quantification of sulfite in highly colored beers (Abrahamsson et al., 2012).

Albeit numerous methods for determining sulfur dioxide in beer have been reported in the literature, the brewing industry is still searching for the ideal procedure. It should be fast, simple, inexpensive, allow for measurement of free or/and total $\mathrm{SO}_{2}$ and exclude the use of toxic reagents. Most of these conditions, or at least a number of them, are met in the aforementioned methods.

\section{Uses of sulfur dioxide in the brewing industry}

Sulfites in various forms have been added to foods for centuries. The usage of sulfiting agents or S (IV) compounds to foods has become widespread because of their varied functional applications such as bleaching agents, antimicrobials, oxygen scavengers, reducing agents and enzyme inhibitors. Sulfur dioxide and several forms of sulfites, which generate sulfur dioxide when used in food, can be used as sulfiting agents. These include sulfur dioxide (E220), potassium bisulfite (potassium hydrogen sulfite) (E228), potassium metabisulfite (E224), sodium bisulfite (sodium hydrogen sulfite) (E222), sodium metabisulfite (E223), sodium sulfite (E221), calcium sulfite (E226) and calcium hydrogen sulfite (E227) after the N ${ }^{\circ}$ 95/2/EC (EC, 1995) Directive. As all the above can convert to sulfur dioxide, sulfites are measured and expressed as sulfur dioxide. Sulfur dioxide found in beer is due not only to the addition of sulfiting agents (exogenous $\mathrm{SO}_{2}$ ) but is also derived from the yeast metabolism or as a component of finings or primings (endogenous $\mathrm{SO}_{2}$ ). Yeast has the ability to produce sulfur dioxide, from the reduction of sulfate in water and grist material. $\mathrm{SO}_{2}$ levels will be increased if the sulfate supply to the yeast is increased, wort clarity is increased, wort oxygenation and pitching rate are lowered and fermentation temperature is reduced (Ilett, 1995). The sources of sulfur dioxide in beer were comprehensively reviewed by Ilett, (1995). Table 2 summarizes the uses of sulfur dioxide in the brewing industry. The different roles of sulfur dioxide on beer flavor stability will be emphasised and discussed below.
Table 2 - Uses of sulfur dioxide in the brewing industry (adapted from llett, 1995).

\begin{tabular}{ll}
\hline $\begin{array}{l}\text { Stage of beer production } \\
\text { germinating }\end{array}$ & $\begin{array}{l}\text { Use of sulfur dioxide } \\
\text { reduce malting losses, enhanced yields of } \\
\text { malt kilning }\end{array}$ \\
$\begin{array}{l}\text { control the formation of nitrosamines, bleach } \\
\text { malt, increase soluble nitrogen }\end{array}$ \\
$\begin{array}{l}\text { kilning of hops } \\
\text { storage of syrups }\end{array}$ & $\begin{array}{l}\text { preservative } \\
\text { storage of finings } \\
\text { fermentation vessels }\end{array}$ \\
$\begin{array}{l}\text { proteolytic enzymes } \\
\text { beer additive }\end{array}$ & $\begin{array}{l}\text { preservative } \\
\text { antioxidant, preservative }\end{array}$ \\
\hline
\end{tabular}

\section{Antioxidant activity of sulfur dioxide in beer}

Antioxidants can be broadly defined as compounds that inhibit an oxidative reaction. They can act by decreasing molecular oxygen levels, scavenging chain-initiating and chain-propagating free radicals, chelating metals, or decomposing peroxides (Halliwell et al., 1987). They are, therefore, thought to have a significant effect in malting and brewing as inhibitors of oxidative damage. In their general reactions, sulfites and hydrogen sulfites are moderatetely strong reducing agents, and together with antioxidant properties, yield either dithionate $\left(\mathrm{S}_{2} \mathrm{O}_{6}{ }^{2-}\right)$ or sulfate $\left(\mathrm{SO}_{4}{ }^{2-}\right)$ upon reaction. This reducing (antioxidant) behavior under all $\mathrm{pH}$ conditions may be seen in the following redox potentials (Senning, 1982):

$$
\begin{array}{lll}
\mathrm{S}_{2} \mathrm{O}_{6}^{2-}+4 \mathrm{H}^{+}+2 \mathrm{e}^{-} & \rightleftarrows 2 \mathrm{H}_{2} \mathrm{SO}_{3} & E^{\circ}=0.564 V \\
\mathrm{SO}_{4}^{2-}+4 \mathrm{H}^{+}+2 \mathrm{e}^{-} & \mathrm{H}_{2} \mathrm{SO}_{3}+\mathrm{H}_{2} \mathrm{O} & E^{\circ}=0.119 V
\end{array}
$$

Beer flavor stability is influenced by a multiplicity of factors; some of them are certainly disputed, but there is no question of the crucial role of oxygen in packaged beer. It has been repeatedly demonstrated that high air levels in the final package greatly reduce shelf life (Back et al., 1999; Bamforth, 2000). Therefore, modern fillers are designed to achieve very low $\mathrm{O}_{2}$ levels and several measures have been adopted in order to keep ingress of oxygen into the packaged beer as low as possible. Various antioxidants may be used in beer (depending on the legislation), with the most prominent of these being sulfur dioxide and ascorbic acid (Bamforth, 1999). These agents can only protect against new oxidation occurring in beer, and do not rectify any damage which has occurred upstream. Sulfur dioxide is the more effective, either in the role of carbonyl binder (discussed below) or radical scavenger.

The production of reactive oxygen species (ROS) is promoted by light and certain enzyme systems. Of particular importance are transition metal ions, such as iron and copper, which are effective in stimulating the formation and multiple-interconversions of radicals 
from oxygen (Bamforth, 2001). The deleterious effect of ROS has led most brewers to make efforts to eliminate these substances from their processes and products. The reactivity of oxygen and its activation by acquisition of electrons was described by Bamforth et al.,(1993) and Hughes, (2000). As oxygen passes successively through superoxide $\left(\mathrm{O}_{2}{ }^{\cdots}\right)$, peroxide $\left(\mathrm{O}_{2}{ }^{2-}\right)$ and hydroxyl (HO $)$ it becomes increasingly reactive. The hydroxyl radical is an immensely reactive species generated in wort and beer, which reacts instantly with a great many types of molecule. Superoxide, on the other hand, is less reactive. At beer pHs, the majority of the superoxide will be in a perhydroxyl form $\left(\mathrm{HO}_{2} \cdot\right)$. Hydroxyl and perhydroxyl are capable of reacting with unsaturated fatty acids, such as linoleic acid, and thereby set in motion a chain reaction that leads to stale flavor development (Bamforth, 2001).

The 1-hydroxyethyl radical, which can be formed by reaction between hydroxyl radical and ethanol, was recently found to be, quantitatively, the most important radical in beer, detectable by electron spin resonance (ESR). Oxidation processes were characterised in beer involving reaction of the 1-hydroxyethyl radical in an important reaction with oxygen, converting it into hydroperoxyl radicals (Andersen and Skibsted, 1998). A number of potential antioxidants have been evaluated for their effect on the formation of radicals in beer using the ESR lag phase method. Sulfite was found to be the only compound that was able to delay the formation of radicals, whereas phenolic compounds such as phenolic acids, catechin, epicatechin, and proanthocyanidin dimers had no effect on the formation of radicals. It was suggested that antioxidants must be able to either scavenge peroxides or trap metal ions in order to be effective in beer. The effectiveness of sulfite was suggested to be a consequence of its two-electron nonradical producing reaction with peroxides (Andersen et al., 2000). Additionally, the concept of Endogenous Antioxidant (EA) value, which is the time taken before an ESR signal is developed in an aging test, showed a clear relationship between the EA value and sulfite level in beer (Uchida and Ono, 2000). More recently, Karabín and co-authors have shown that one of the reasons for the decline in the endogenous antioxidative potential of beer during storage is a significant decrease in $\mathrm{SO}_{2}$ content, probably caused by chain oxidation reactions catalysed by transition metal ions, particularly ferric ions (Karabin et al., 2014).

It is postulated that the deterioration rates of beers might be assessed from the chemiluminescence (CL) producing patterns in fresh beer before storage. The presence of sulfite in beer depressed CL production during its storage indicating that there is some contribution of sulfite to flavor stability due to its inhibitory effect on radical reactions (Kaneda et al., 1994). Formaldehydeand acetaldehyde-bisulfite adducts inhibited the chemiluminescence production of beer and Cypridina lucifern analog dependent luminescence in beer, indicating that they inhibit free radical reactions. Therefore, it could be concluded that aldehyde-bisulfite adducts have radical scavenging activity and protect free radical chain reactions during beer storage, leading to stability of beer quality (Kaneda et al., 1994). Additionally, it was shown by Kaneda and co-authors that the lower the dissolved oxygen in pitching wort, the higher the pitching rate of yeast. Clearer pitching wort leads to higher sulfite content level, inhibition of CL production, and better flavor stability of the resulting beers (Kaneda et al., 1992). Lermusieau and co-authors confirmed in laboratory-scale experiments that $\mathrm{SO}_{2}$ can reduce both lipid autooxidation and the nonenal potential rise while the wort is boiling (Lermusieau et al., 1999).

Much of the $\mathrm{SO}_{2}$ added to beers is rapidly bound up with components other than carbonyls, with an addition of 20 ppm revealing only approximately 12 ppm of measurable total $\mathrm{SO}_{2}$. The majority of this is lost through aging, especially in the presence of high levels of air (Bushnell et al., 2003). Recent sensory and chemical evidence from Bushnell and co-authors support the argument that sulfites exert their protective effect as antioxidants rather than as agents that bind carbonyls as adducts.

\section{Formation of adducts with carbonyl compounds}

Sulfur dioxide reacts with a wide range of food components. It forms adducts by reversible action with aldehydes and ketones (including reducing sugars, acetaldehyde, quinones, and ketoacids), with anthocyanins, and with cysteine residues in proteins. In most foods and beverages, adducts with carbonyl compounds, the hydroxysulfonates (Figure 2), comprise most of the bound sulfite, and this equilibrium reaction has been studied in detail. In the range $\mathrm{pH} 1$ to 8 the hydroxysulfonates predominate, while at higher $\mathrm{pH}$ values dissociation occurs (Adachi et al., 1979). It is also believed that sulfite stabilizes intermediates of the Maillard reaction by forming adducts. For example, glyceraldehyde forms stable hydroxysulfonate adduct, which could contribute to the mechanism of the inhibition of Maillard browning by sulfite species (Keller et al., 1999). Dissociation constants of carbonyl bisulfite compounds at $\mathrm{pH} 3.5$ have been reported by Azevedo et al., (2007). They revealed that aliphatic aldehydes form adducts with S (IV), whereas ketones, cyclic aldehydes, and trans-alkenes interact weakly and are found predominantly in the free form. Range of dissociation constants of bisulfite compounds are $1.09 \times 10^{-7}$ for formaldehyde, $2.06 \times 10^{-6}$ for acetaldehyde, $3.45 \times 10^{-6}$ for hexanal, $2.52 \times 10^{-6}$ for octanal and $1.33 \times 10^{-4}$ for hexan-2-one. Determination of the

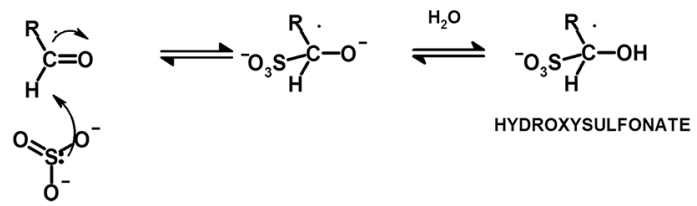

Figure 2 - Formation of $\alpha$-hydroxysulfonates by the addition reaction of sulfite to the carbonyl group. 
predicted sulfite binding power was carried out by Lea and co-authors. They found equilibrium constants of 1.6 $\times 10^{-4}$ for pyruvate, $1.8 \times 10^{-2}$ for galacturonic acid and $6.4 \times 10^{-1}$ for glucose (Lea et al., 2000). The equilibrium constants remain fairly constant between $\mathrm{pH} 2$ to 6 , a $\mathrm{pH}$ range that encompasses all beers. At $\mathrm{pH}>7$ dissociation of adducts is favored to give the free carbonyl.

Beer flavor instability is caused by the formation of volatile, long chain, unsaturated carbonyls with low flavor thresholds and unpleasant flavors. Long chain unsaturated aldehydes, such as E-2-nonenal which contributes a cardboard-like flavor, are prime contributors (Huige, 2009). Sulfite, produced by yeast during fermentation or added before bottling, readily form adducts with carbonyl compounds, rendering them nonvolatile and flavour-inactive (Nyborg et al., 1999). As a result, $\mathrm{SO}_{2}$ plays a role in masking the stale flavors that develop in beer during storage. Appearance of the cardboard flavor in aged beer is strongly retarded when such beers are supplemented with sulfite. The papery, cardboard stage of beer staling was ascribed to a decrease in bisulfite concentration and subsequent bisulfite transfer from unsaturated aldehyde bisulfite addition complexes (Barker et al., 1983). Nyborg and co-authors demonstrated that flavor-active $E$-2-nonenal has disappeared from the beer upon addition of sulfite, suggesting the formation of flavor-inactive adducts (Nyborg et al., 1999). They confirmed the adduct formation between $E$-2-nonenal and sulfite in aqueous solution at beer $\mathrm{pH}$ indirectly by ${ }^{1} \mathrm{H}$ NMR spectroscopy and directly by liquid chromatography coupled to mass spectrometry (LC-MS). Dufour and co-authors have showed, using the unsaturated aldehyde $E$-2-butenal to model the behaviour of $E$-2-nonenal, that the mechanism of the addition reaction proceeds by a two-step process, to initially give a carbonyl adduct and ultimately yield a disulfonate as the thermodynamic product, as illustrated in the Figure 3 (Dufour et al., 1999). A reversible binding occurs between the carbonyl functional group and bisulfite, whereas the addition of bisulfite to the double bound of unsaturated aldehydes was shown to be irreversible. The stability of such adducts does not support the generally accepted mechanism for the release of unsaturated aldehydes from non-volatile species.

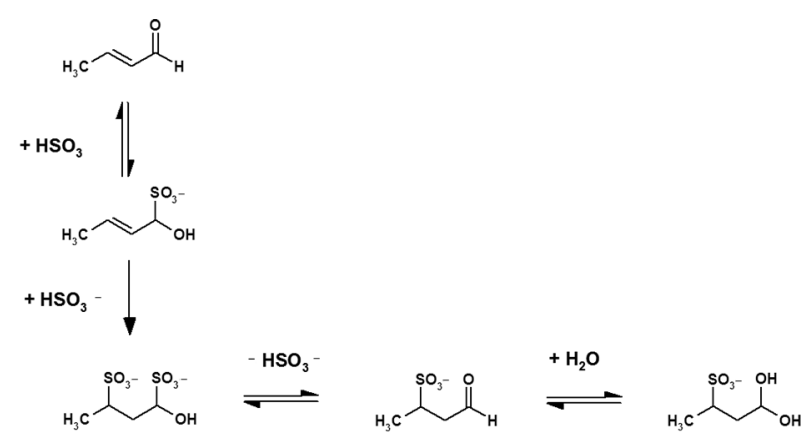

Figure 3 - Equilibria of E-2-butenal based on the ${ }^{1} \mathrm{H}-\mathrm{NMR}$ kinetic data proposed by Dufour et al., (1999).
The protective effect of sulfite against beer staling is not a passive event. During fermentation, the bisulfite excreted by yeast can potentially bind to the carbonyl compounds present in the medium, and prevent them from being reduced by yeast into the corresponding alcohols. These adducts might pass into beer, where they progressively break down to free the carbonyls which render the beer stale. Thus, brewers have contradictory opinions on the efficiency of naturally produced bisulfite by yeast as compared to that added to the beer before bottling (Dufour et al., 1999). Partial or full elimination of MET10 gene activity in brewer's yeast resulted in increased sulfite accumulation. Beer produced with such yeasts was quite satisfactory and showed increased flavor stability (Hansen and KiellandBrandt, 1996).

Acetaldehyde has a far greater capacity for binding bisulfite than have the staling aldehydes and its presence interferes with the ability of agents to bind staling substances (Bamforth, 2000). Studies on the behavior of sulfites during fermentation and storage of beer revealed that acetaldehyde-bisulfite adduct and free sulfite produced during fermentation are oxidized by free radical reactions during beer storage and inhibit the oxidation of the other beer components (Kaneda et al., 1996a; Kaneda et al., 1996b). These observations most likely explain the increase obtained for the ratio of acetaldehyde and $\mathrm{SO}_{2}$ during extended storage of beer. Using a voltammetric-based approach, the formation of an acetaldehyde-sulfite adduct was followed, and showed that the reaction is rapid and equilibrium is reached after 30 minutes (Guido et al., 2003).

The complexity of carbonyl-bisulfite adducts formation is enhanced if the release mechanism of the carbonyl compounds from their adducts with amino acids and proteins of the wort is considered. Within the $\mathrm{pH}$ range of wort, a Schiff base formation is proposed between carbonyl compounds and either free amino acids or proteins (Noel et al., 1999; Lermusieau et al., 1999). ${ }^{1} \mathrm{H}-\mathrm{NMR}$ evidence of model systems suggest that $\mathrm{N}$-adducts of alkenals, Michael adducts and Schiff bases, are relatively unstable particularly in the presence of bisulfite (Dufour et al., 2000). Formation of carbonyl-adducts and their subsequent release appears to interact in a complicated and dynamic way. Various linked equilibria, including those involving sulfite, are responsible for the release of carbonyl compounds and, thus, for the stale character typical of aged beers.

\section{The dualistic mode of action of sulfites}

In terms of the contribution of sulfite to control flavor instability of beer, a dualistic mode of action has been proposed (Figure 4). Firstly, sulfite inhibits beer oxidation during storage by acting as an antioxidant. Sulfite has radical scavenging activity and avoids the free radical chain reactions during beer storage, and contributes to the stability of beer quality. Secondly, sulfite can react with the carbonyl staling compounds in beer, which 


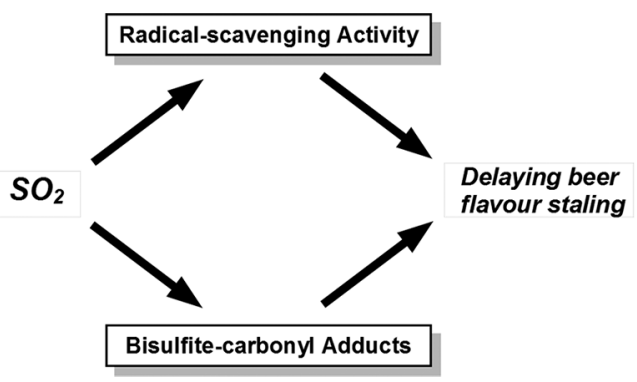

Figure 4 - The dualistic mode of action of sulfites to control the flavor instability of beer.

masks stale flavors. Adducts formed are non-volatile and, therefore, have much higher flavor thresholds than free carbonyls.

The most effective role of $\mathrm{SO}_{2}$ in delaying flavor staling of beer, beit acting as an antioxidant or masking stale flavors, is still an open question. Sulfur dioxide is progressively lost from beer in a first order reaction. The constant rate for the reaction increased as the temperature increased in the range of 0 to $40{ }^{\circ} \mathrm{C}$ and was dependent to some extent, on the initial $\mathrm{SO}_{2}$ concentration. Storage of beer at $0{ }^{\circ} \mathrm{C}$ considerably reduced the rate of $\mathrm{SO}_{2}$ loss, but did not prevent it (Ilett and Simpson, 1995). Lowering the temperature is, thus, the main measure that must be adopted by the brewer in an attempt to minimize the loss of $\mathrm{SO}_{2}$ and to successfully preserve the overall flavor quality of the final product.

\section{Acknowledgements}

The author is grateful to the Foundation for Science and Technology Portugal (FCT) for his Sabbatical Leave Grant (SFRH/BSAB/1272/2012). This study also received financial support from the European Union (FEDER funds) under the framework of QREN through Project NORTE-07-0124-FEDER-000069.

\section{References}

Abrahamsson, V.; Hoff, S.; Nielsen, N.J.; Lund, M.N.; Andersen, M.L. 2012. Determination of sulfite in beer based on fluorescent derivatives and liquid chromatographic separation. Journal of the American Society of Brewing Chemists 70: 296-302.

Adachi, T.; Nonogi, H.; Fuke, T.; Ikuzawa, M.; Fujita, K.; Izumi, T.; Hamano, T.; Mitsuhashi, Y.; Matsuki, Y.; Suzuki, H.; Toyoda, M.; Ito, Y.; Iwaida, M. 1979. Combination of sulfite with food ingredients (aldehydes, ketones and sugars) .II. Zeitschrift fur Lebensmittel-Untersuchung und Forschung 168: 200-205.

Agência Nacional de Vigilância Sanitária [ANVISA]. 2011. Resolução RDC No 65, de 29 de novembro de 2011. Dispõe sobre a aprovação de uso de aditivos alimentar para fabricação de cervejas. Anvisa, Brasília, DF, Brazil. (in Portuguese).

Almeida, P.J.; Rodrigues, J.A.; Guido, L.F.; Santos, J.R.; Barros, A.A.; Fogg, A.G. 2003. Voltammetric determination of free and total sulfur dioxide in beer. Electroanalysis 15: 587-590.
Andersen, M.L.; Outtrup, H.; Skibsted, L.H. 2000. Potential antioxidants in beer assessed by ESR spin trapping. Journal of Agricultural and Food Chemistry 48: 3106-3111.

Andersen, M.L.; Skibsted, L.H. 1998. Electron spin resonance spin trapping identification of radicals formed during aerobic forced aging of beer. Journal of Agricultural and Food Chemistry 46: 1272-1275.

Atanassov, G.; Lima, R.C.; Mesquita, R.B.R.; Rangel, A.O.S.S.; Tóth, I.V. 2000. Spectrophotometric determination of carbon dioxide and sulphur dioxide in wines by flow injection. Analusis 28: 77-82.

Azevedo, L.C.; Reis, M.M.; Motta, L.F.; Rocha, G.O.; Silva, L.A.; Andrade, J.B. 2007. Evaluation of the formation and stability of hydroxyalkylsulfonic acids in wines. Journal of Agricultural and Food Chemistry 55: 8670-8680.

Back, W.; Forster, C.; Krottenthaler, M.; Lehmann, J.; Sacher, B.; Thum, B. 1999. New research findings on improving taste stability. Brauwelt International 5: 394-405.

Bamforth, C.W. 1999. The science and understanding of the flavour stability of beer: a critical assessment. Brauwelt International 2: 98-110.

Bamforth, C.W. 2000. Making Sense of Flavor Change in Beer. MBAA Technical Quarterly 37: 165-171.

Bamforth, C.W. 2001. Oxido-reduction processes and active forms of oxygen in aqueous systems. Cerevisia 26: 149-154.

Bamforth, C.W.; Muller, R.E.; Walker, M.D. 1993. Oxygen and oxygen radicals in malting and brewing: a review. Journal of the American Society of Brewing Chemists 51: 79-81.

Barker, R.L.; Gracey, D.E.F.; Irwin, A.J.; Pipasts, P.; Leiska, E. 1983. Liberation of staling aldehydes during storage of beer. Journal of the Institute of Brewing 89: 411-415.

Bendtsen, A.B.; Jorgensen, S.S. 1994. Determination of total and free sulfite in unstabilized beer by flow-injection analysis. Journal of AOAC International 77: 948-951.

Bubnis, B. 1988. Methods of determining sulfites in beer and other beverages. Brewers' Digest 63: 20-21.

Burmeister, M.S.; Drummond, C.J.; Pfisterer, E.A.; Hysert, D.W. 1992. Measurement of volatile sulfur compounds in beer using gas chromatography with a sulfur chemiluminescence detector. Journal of the American Society of Brewing Chemists 50: 53-58.

Bushnell, S.E.; Guinard, J.X.; Bamforth, C.W. 2003. Effects of sulfur dioxide and polyvinylpolypyrrolidone on the flavor stability of beer as measured by sensory and chemical analysis. Journal of the American Society of Brewing Chemists 61: 133-141.

Cremer, H.D.; Hotzel, D. 1970. Thiamine deficiency and sulfite metabolism in humans. 4. Results and summary of findings in human metabolism. Internationale Zeitschrift Vitaminforschung 40: 52-57.

Decnop-Weever, L.G.; Kraak, J.C. 1997. Determination of sulphite in wines by gas-diffusion flow injection analysis utilizing spectrophotometric $\mathrm{pH}$-detection. Analytica Chimica Acta 337: 125-131.

Dufour, J.P.; Leus, M.; Baxter, A.J.; Hayman, A.R. 1999. Characterization of the reaction of bisulfite with unsaturated aldehydes in a beer model system using nuclear magnetic resonance spectroscopy. Journal of the American Society of Brewing Chemists 57: 138-144. 
Dufour, J.P.; Leus, M.; Hayman, A.R. 2000. Chemical equilibria of beer staling: reaction of bisulfite with unsaturated aldehydes. Frontiers of Flavour Science: 579-583.

Dvořák, J.; Dostálek, P.; Štěrba, K.; Čejka, P.; Kellner, V.; Čulík, J.; Beinrohr, E. 2006. Determination of total sulphur dioxide in beer samples by flow-through chronopotentiometry. Journal of the Institute of Brewing 112: 308-313.

Greenwood, N.N.; Earnshaw, A. 1999. Chemistry of the Elements. Elsevier, Amsterdam, The Netherlands

European Brewery Convention [EBC]. 1987. Analytica-EBC. Brauerei-und Getranke-Rundschau, Zurich, Switzerland.

European Communities [EC]. 1995. European Parliament and Council Directive 95/2/EC on food additives other than colours and sweeteners. Official Journal of the European Communities L 61/1.

European Communities [EC]. 2000. Directive 2000/13/EC of the European Parliament and of the Council of 20 March 2000 on the approximation of the laws of the Member States relating to the labelling, presentation and advertising of foodstuffs. Official Journal of the European Communities L 109.

Fazio, T. 1988. Sulfite methodology. Brewers' Digest 63: 16-18.

Fazio, T.; Warner, C.R. 1990. A review of sulfites in foods: analytical methodology and reported findings. Food Additives and Contaminants 7: 433-454.

Food and Drug Administration [FDA]. 1988. Sulfiting Agents: Affirmation of GRAS Status. Fed. Reg 53: 51065-51084. FDA, Washington, DC, USA.

Fernandes, S.M.V.; Rangel, A.O.S.S.; Lima, J.L.F.C. 1998. Determination of total sulphur dioxide in beer by flow injection spectrophotometry using gas-diffusion and the merging zones technique. Journal of the Institute of Brewing 104: 203-205.

Gonçalves, L.M.; Pacheco, J.G.; Magalhães, P.J.; Rodrigues, J.A.; Barros, A.A. 2010. Determination of free and total sulfites in wine using an automatic flow injection analysis system with voltammetric detection. Food Additives \& Contaminants: Part A 27: 175-180.

Government of Canada. 2015. Regulations respecting food and drugs. Available at: http://laws-lois.justice.gc.ca.

Guido, L.F.; Fortunato, N.A.; Rodrigues, J.A.; Barros, A.A. 2003. Voltammetric assay for the aging of beer. Journal of Agricultural and Food Chemistry 51: 3911-3915.

Halliwell, B.; Gutteridge, J.M.; Aruoma, O.I. 1987. The deoxyribose method: a simple "test-tube" assay for determination of rate constants for reactions of hydroxyl radicals. Analytical Biochemistry 165: 215-219.

Hansen, J.; Kielland-Brandt, M.C. 1996. Inactivation of MET10 in brewer's yeast specifically increases $\mathrm{SO} 2$ formation during beer production. Nature Biotechnology 14: 1587-1591.

Holak, W.; Patel, B. 1987. Differential pulse polarographic determination of sulfites in foods: collaborative study. Journal of Association of Official Analytical Chemists 70: 572-578.

Hughes, P. 2000. Reducing power and sulphur compounds implications and functions in beer. Cerevisia 25: 59-66.

Huige, N.J. 2009. Progress in beer oxidation control. p. 64-97. In: Gump, B.H.; Pruett, D.J., eds. Beer and wine production: analysis, characterization and technological advances. American Chemical Society, Washington, DC, USA.
Ilett, D.R. 1995. Aspects of the analysis, role, and fate of sulphur dioxide in beer: a review. MBAA Technical Quarterly 32: 213221.

Ilett, D.R.; Simpson, W.J. 1995. Loss of sulfur-dioxide during storage of bottled and canned beers. Food Research International 28: 393-396.

Kaneda, H.; Kano, Y.; Sekine, T.; Ishii, S.; Takahashi, K.; Koshino, S. 1992. Effect of pitching yeast and wort preparation on flavor stability of beer. Journal of Fermentation and Bioengineering 73: 456-460.

Kaneda, H.; Osawa, T.; Kawakishi, S.; Munekata, M.; Koshino, S. 1994. Contribution of carbonyl-bisulfite adducts to beer stability. Journal of Agricultural and Food Chemistry 42: 24282432.

Kaneda, H.; Takashio, M.; Osawa, T.; Kawakishi, S.; Koshino, S.; Tamaki, T. 1996a. Analysis of aldehyde-bisulfites in beer by HPLC-fluorescence detection with post-column derivatization. Journal of Food Science 61: 105-108.

Kaneda, H.; Takashio, M.; Osawa, T.; Kawakishi, S.; Tamaki, T. 1996b. Behavior of sulfites during fermentation and storage of beer. Journal of the American Society of Brewing Chemists 54: 115-120.

Karabin, M.; Ryparova, A.; Jelinek, L.; Kunz, T.; Wietstock, P.; Methner, F.; Dostalek, P. 2014. Relationship of iso-alphaacid content and endogenous antioxidative potential during storage of lager beer. Journal of the Institute of Brewing 120: 212-219.

Keller, C.; Wedzicha, B.L.; Leong, L.P.; Berger, J. 1999. Effect of glyceraldehyde on the kinetics of Maillard browning and inhibition by sulphite species. Food Chemistry 66: 495-501.

Kim, H.J. 1990. Determination of sulfite in foods and beverages by ion exclusion chromatography with electrochemical detection: collaborative study. Journal of Association of Official Analytical Chemists 73: 216-222.

Lea, A.G.H.; Ford, G.D.; Fowler, S. 2000. Analytical techniques for the estimation of sulphite binding components in ciders and wines. International Journal of Food Science and Technology 35: $105-112$

Lermusieau, G.; Noel, S.; Liegeois, C.; Collin, S. 1999. Nonoxidative mechanism for development of trans-2-nonenal in beer. Journal of the American Society of Brewing Chemists 57: 29-33.

Lester, M.R. 1995. Sulfite Sensitivity: significance in human health. Journal of the American College of Nutrition 14: 229232.

Li, Y.J.; Zhao, M.P. 2006. Simple methods for rapid determination of sulfite in food products. Food Control 17: 975-980.

Maquieira, A.; Casamayor, F.; Puchades, R.; Sagrado, S. 1993. Determination of total and free sulfur dioxide in wine with a continuous-flow microdistillation system. Analytica Chimica Acta 283: 401-407.

Moreno, L.R.; Vega, P.I. 1989. Headspace gas chromatographic analysis of sulfur dioxide in beer. Journal of the American Society of Brewing Chemists: 6-9.

Munar, M.; Maurice, M.J.; Kluessendorf, A. 1994. Quantitation of sulfur-dioxide residues in malt and beer by headspace gaschromatography. Journal of the American Society of Brewing Chemists 52: 168-171. 
Noel, S.; Liegeois, C.; Lermusieau, G.; Bodart, E.; Badot, C.; Collin, S. 1999. Release of deuterated nonenal during beer aging from labeled precursors synthesized in the boiling kettle. Journal of Agricultural and Food Chemistry 47: 4323-4326.

Nyborg, M.; Outtrup, H.; Dreyer, T. 1999. Investigations of the protective mechanism of sulfite against beer staling and formation of adducts with trans-2-nonenal. Journal of the American Society of Brewing Chemists 57: 24-28.

Osborne, S. 1992. Dedicated sulphur detector to improve flavor control. Brewing and Distilling International 23: 15.

Richter, P.; Decastro, M.D.L.; Valcarcel, M. 1993. Spectrophotometric flow-through sensor for the determination of sulfur-dioxide. Analytica Chimica Acta 283: 408-413.

Scientific Committee on Food [SCF]. 1994. Opinion on Sulfur Dioxide and Other Sulphiting Agents Used as Food Preservatives. European Commission, Brussels, Belgium.

Senning, A. 1982. Sulfur in Organic and Inorganic Chemistry. Marcel Dekker, New York, NY, USA.

Stonys, D.B. 1987. Determination of sulfur dioxide in foods by modified Monier-Williams distillation and polarographic detection. Journal of Association of Official Analytical Chemists 70: 114-117.

U.S. Government Publishing Office [GPO]. 2000. Title 27: Alcohol, Tobacco Products and Firearms, Part 7: Labeling and Advertising of Malt Beverages, Subpart C: Labeling Requirements for Malt Beverages. Electronic Code of Federal Regulations. GPO, Washington, DC, USA.
Uchida, M.; Ono, M. 2000. Technological approach to improve beer flavor stability: adjustments of wort aeration in modern fermentation systems using the electron spin resonance method. Journal of the American Society of Brewing Chemists 58: 30-37.

Wagner, H.P.; McGarrity, M.J. 1991. The use of pulsed amperometry combined with ion-exclusion chromatography for the simultaneous analysis of ascorbic-acid and sulfite. Journal of Chromatography 546: 119-124.

Wagner, H.P.; McGarrity, M.J. 1992. Determination of sulphite in beer using ion exclusion chromatography and pulsed amperometric detection. Journal of the American Society of Brewing Chemists 50: 1-3.

Wedzicha, B.L. 1984. Chemistry of Sulfur Dioxide in Foods. Elsevier, Amsterdam, The Netherlands.

Wygant, M.B.; Statler, J.A.; Henshall, A. 1997. Improvements in amperometric detection of sulfite in food matrixes. Journal of AOAC International 80: 1374-1380.

Zeller, S. 1988. Use of an automatic coulometer for sulfur determinations. Brewers Digest 63: 24-27. 